Methods: Patients with RA from two teaching hospitals, participating in a prospective observational study completed the HAQ-DI and EQ5D-5L at 0-6-12 month follow-up visits. Inclusion criteria: ACR RA diagnosed patients, on biologic treatment and whose disease activity remained stable at least for 3 months EQ5D-5L is a standardized, generic instrument for describing and valuing health and QoL, consisting in a five-dimensional descriptive system (mobility, self-care, usual activities, pain/discomfort and anxiety/depression) and a visual analogue scale. A country-specific tariff converts patient's answer to a $0-1$ (full health) utility index. HAQ-DI is a self-completed questionnaire used to assess the functional ability using 20 items, distributed across 8 dimensions and resulting in a four-level disability scale (0-3). In addition, socio-demographic and clinical data where recorded.To estimate the EQ5D-5L utility index OLS models were built. As this index is bounded to the $[-0.416,1]$ interval, Tobit models were also considered. Hereafter, the index was transformed to the open interval $(0,1)$ and estimated through beta regression with a logit link. To determine the relationship grade between the index and the HAQ-DI scale and obtain residuals without trend, GAM models were used. Best fitting models were determined by AIC, MAE and RMSE. All analyses were performed using $R$ software

Results: 217 questionnaires fulfilled by 77 patients. Mean (SD) age was 57.0 (12.9), 87\% women, AR duration 13.7 (7.1), mean DAS28 2.72 (1.00) and HAQ-DI 0.77 (0.60). Baseline EQ5D index: $0.768(0.182)$. All the OLS estimation models resulted in the interval limits defined by the index, so Tobit models were not considered. When considering the linear model we obtained the best results with the HAQ-DI term and its third power: EQ5D5L $=0.9232-0.1760 \times \mathrm{HAQ}-$ $0.0172 \times \mathrm{HAQ}^{3}(\mathrm{AIC}=-221.62 ; \mathrm{MAE}=0.0974 ; \mathrm{RMSE}=0.1363)$; for beta regression, we obtained the best model with the HAQ-DI to the first power alone: logit $(\mathrm{EQ} 01)=2.5821-1.1165 \times \mathrm{HAQ}(\mathrm{AIC}=-444.4 ; \mathrm{MAE}=0.0691 ; \mathrm{RMSE}=0.0958)$. Considering the AIC and the residuals together, we obtained the best fitting model with the beta regression approach, with neither age nor sex

Conclusions: So far, only a utility function using HAQ-DI and an older EQ5D-3L version was available for Spain (Carreño,2011). This updated utility function can be used as a practical approach to predict RA patients' QoL and EQ5D utility score for Spain when clinicians/researchers need them for clinical practice or cost-effectiveness analyses and generic QoL measurements are not available

Disclosure of Interest: None declared

DOI: 10.1136/annrheumdis-2017-eular.4836

\section{THU0110 THE IMPORTANCE OF SUSTAINED REMISSION FOR LONGTERM OUTCOMES IN PATIENTS WITH RHEUMATOID ARTHRITIS}

J. Smolen ${ }^{1}$, C. Gabay ${ }^{2}$, D. Aletaha ${ }^{1}$, P. Emery ${ }^{3}$, I. Sainsbury ${ }^{4}$, Y. Zhang ${ }^{4}$, A. Kavanaugh ${ }^{5}$. ${ }^{1}$ Medical Univ of Vienna, Vienna, Austria; ${ }^{2}$ Univ of Geneva, Geneva, Switzerland; ${ }^{3}$ Leeds Inst of Rheumatic \& Musculoskeletal Medicine, Leeds, United Kingdom; ${ }^{4}$ AbbVie, N Chicago, IL; ${ }^{5}$ Univ of California, San Diego, $C A$, United States

Background: In patients (pts) with rheumatoid arthritis (RA), the long-term impact of sustained versus (vs) transient clinical remission (REM) has not been assessed thoroughly, although REM duration has been shown to affect structural outcomes $^{1}$. The relationship of different definitions of clinical remission (REM) with function and structural integrity has not been assessed.

Objectives: To explore the importance of sustained REM or disease control for long-term outcomes, and assess various definitions of REM in adalimumab (ADA) long-term trials.

Methods: Data are from 2 trials of ADA in early RA pts; In PREMIER, pts received $A D A$, methotrexate (MTX) or ADA+MTX for 2 years (yrs), after which they could enter an open label (OL) period for upto $8 \mathrm{yrs}^{2}$. In OPTIMA, pts received $A D A+M T X$, or placebo (PBO) +MTX for 26 weeks (wks). Based on whether or not pts achieved DAS28-CRP $<3.2$ at wks 22 and 26, pts withdrew ADA, continued on PBO+MTX, ADA+MTX or OL ADA+MTX until Wk $78^{3}$. For this analysis, non-sustained REM/disease control was defined as meeting one of the following at 6 months but not $1 \mathrm{yr}$ : DAS28-CRP $<2.6$; simplified disease activity index $(\mathrm{SDAl}) \leq 3.3$; clinical disease activity index $(\mathrm{CDAl}) \leq 2.8$. Sustained $\mathrm{REM} /$ disease control was defined as meeting these criteria at both 6 months and $1 \mathrm{yr}$. The mean change from baseline in health assessment questionnairedisability index $(\triangle \mathrm{HAQ}-\mathrm{DI})$, or modified total Sharp score $(\Delta \mathrm{mTSS})$, and the number of pts without clinical worsening of HAQ-DI $(\Delta \leq 0.22)$ were assessed over 78 wks for OPTIMA, or 5 yrs for PREMIER. NRI and LOCF were used for binary and continuous variables, respectively.

Results: In OPTIMA, by any of the REM criteria, pts in sustained REM had larger mean $\triangle \mathrm{HAQ}-\mathrm{DI}$ over time (Fig $1 \mathrm{~A})$ vs pts in non-sustained REM. Pts with non-sustained DAS28-CRP $<2.6$ vs non-sustained CDAI REM had numerically smaller $\triangle \mathrm{HAQ}$-DI up to Wk 52. Over time, more pts in sustained vs non-sustained REM using DAS28-CRP $<2.6$ (but not CDAI or SDAl criteria) did not have clinical worsening of $\mathrm{HAQ}-\mathrm{DI}$, possibly due to more suppression of inflammatory components upon achieving CDAI REM but not DAS28-CRP $<2.6$ in these early RA pts (Fig 1B). At Wk 78, $\triangle$ mTSS at Wk 78 was smaller for pts in sustained vs non-sustained DAS28-CRP $<2.6$, and similar for sustained and non-sustained CDAI REM (Fig 1C). Somewhat fewer pts at Wk 78 may have contributed to some variability. Trends were similar in PREMIER (not shown).

Conclusions: Pts who were in sustained disease control/REM had better clinical, functional and radiographic outcomes over the long- term, vs pts in a
A
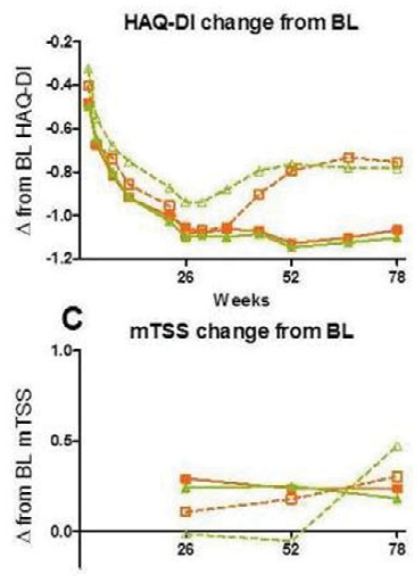

For LOCF: CDAl non-sustained REM N=28, CDAl sustained REM N=84,

DAS28 $<2.6$ non-sustained, $\mathrm{N}=39, \mathrm{OAS} 28<2.6$ sustained, $\mathrm{N}=137$;

For NRI: CDAi non-sustained REM at Wk 26, $\mathrm{N}=22$, at Wk $78, \mathrm{~N}=18$; CDAl sustained REM at Wk $26, \mathrm{~N}=59$, at Wk $78, \mathrm{~N}=56$ DAS28 $<2.6$ non-sustained, at Wk 26, N=23, at Wk 78, N=21; DAS28 <2.6 sustained, at Wk 26, N=95, at Wk $78, \mathrm{~N}=90$

more transient state, regardless of the REM criteria used, although for CDAI REM, functional and radiographic outcomes were similar for sustained and non-sustained REM, in line with its higher stringency.

References:

[1] Aletaha et al, Arthritis \& Rheum. 2009;5:1242.

[2] Breedveld et al. 2006. Arthritis \& Rheum;54:26.

[3] Smolen et al. 2014. Lancet;383:321.

Acknowledgements: AbbVie: study sponsor, contributed to design, data collection, analysis, interpretation; and writing, reviewing, approval of final version. Medical writing: Naina Barretto, of AbbVie.

Disclosure of Interest: J. Smolen: None declared, C. Gabay Grant/research support from: AbbVie Inc, Amgen, BMS, MSD, Pfizer, Roche, Celgene, Sanofi, and Regeneron., Consultant for: AbbVie Inc, Amgen, BMS, MSD, Pfizer, Roche, Celgene, Sanofi, and Regeneron., D. Aletaha Grant/research support from: AbbVie Inc., Pfizer, Grünenthal, Merck, Medac, UCB, Mitsubishi/Tanabe, Janssen, and Roche., Consultant for: AbbVie Inc., Pfizer, Grünenthal, Merck, Medac, UCB, Mitsubishi/Tanabe, Janssen, and Roche., P. Emery Grant/research support from: research grants and consulting fees from Pfizer, MSD, AbbVie Inc., Bristol-Myers Squibb, UCB, Roche, Novartis, Samsung, Sandoz and Lilly., Consultant for: research grants and consulting fees from Pfizer, MSD, AbbVie Inc., Bristol-Myers Squibb, UCB, Roche, Novartis, Samsung, Sandoz and Lilly., I. Sainsbury Employee of: AbbVie, Y. Zhang Employee of: AbbVie, A. Kavanaugh Grant/research support from: AbbVie Inc., Amgen, Astra-Zeneca, BMS, Celgene, Centocor-Janssen, Pfizer, Roche, and UCB., Consultant for: AbbVie Inc., Amgen, Astra-Zeneca, BMS, Celgene, Centocor-Janssen, Pfizer, Roche, and UCB.

DOI: 10.1136/annrheumdis-2017-eular.2779

\section{THU0111 NOVEL AUTOANTIBODY PROFILES IN RHEUMATOID ARTHRITIS AND THEIR ASSOCIATION WITH RADIOGRAPHIC PROGRESSION IN THE SCOTTISH EARLY RHEUMATOID ARTHRITIS INCEPTION COHORT AND BIOBANK (SERA)}

J. Nijjar $^{1}$, F. Morton ${ }^{1}$, A. Gilmour ${ }^{1}$, C. Paterson ${ }^{1}$, H. Bang ${ }^{2}$, D. van der Heijde ${ }^{3}$, K. Raza ${ }^{4}$, C. Buckley ${ }^{4}$, D. Porter ${ }^{5}$, I. Mclnnes ${ }^{1}$. ${ }^{1}$ University of Glasgow, Glasgow, United Kingdom; ${ }^{2}$ Orgentec Diagnostika GmbH, Mainz, Germany; ${ }^{3}$ LUMC, Leiden, Netherlands; ${ }^{4}$ University of Birmingham, Birmingham; ${ }^{5} \mathrm{NHS}$ GGC, Glasgow, United Kingdom

Background: Antibodies against citrullinated peptides are useful in the diagnosis of rheumatoid arthritis (RA) and are associated with poorer prognosis and greater radiographic progression. Novel autoantibodies recognising several posttranslational modifications (PTM) are now emerging including anti-carbamyl, and anti-acetyl antibody classes. Less is known of their prognostic significance.

Objectives: To determine the prevalence of autoantibodies to modified vimentin and/or CCP2 (anti citrullinated (CCP), anti carbamylated (Carb), anti acetylated (Acet)) in a subset of the Scottish Early RA (SERA) inception cohort $(n=212)$ and to correlate them with baseline and radiographic progression over 12 months. Methods: Baseline and $12 \mathrm{~m}$ hand and foot radiographs were scored by two readers independently, blinded to patient information and time order according to the Sharp van der Heijde score (SvH). Serum samples from the SERA biobank were analysed with recently published anti-modified protein assays. Patients with citrullinated antibodies (CCP) had antibodies to modified vimentin and/or antibodies to CCP2. Clinical, radiographic and autoantibody data were analysed in $\mathrm{R}$.

Results: See Table 1

In patients with early RA four main antibody profiles were detected: patients 


\begin{tabular}{lcccc} 
Table 1 & $\begin{array}{c}\text { Negative } \\
\mathrm{n}=35\end{array}$ & $\begin{array}{c}\mathrm{CCP} \\
\mathrm{n}=65\end{array}$ & $\begin{array}{c}\text { CCP_Carb } \\
\mathrm{n}=36\end{array}$ & $\begin{array}{c}\text { CCP_Carb_Acet } \\
\mathrm{n}=76\end{array}$ \\
\hline Female (\%) & 74.1 & 72.3 & 66.75 & 52.6 \\
Age, mean & 64.1 & 54.9 & 60.5 & 56.7 \\
Disease duration, mean, months & 6.6 & 14.7 & 11.7 & 13.2 \\
Smoked (\%) & 54.3 & 67.7 & 77.8 & 67.1 \\
DAS28-ESR, mean (complete data) & $5.5(30)$ & $4.7(56)$ & $5.1(30)$ & $5.2(64)$ \\
Radiographic Scores & & & & \\
$\quad$ Baseline Erosion score, mean & 2.9 & 2.8 & 7.2 & 3.3 \\
$\quad$ Baseline JSN score, mean & 3.3 & 3.4 & 6.6 & 3.5 \\
$\quad$ Baseline Total SvH Score, mean & 6.2 & 6.2 & 13.8 & 6.8 \\
$\quad$ Mean change in Total SvH score over & & & & \\
$\quad$ 12 months & 0.5 & 0.5 & 1 & 1.8 \\
\hline
\end{tabular}

with anti CCP antibodies ( $n=65)$, antibodies to anti CCP and anti Carb $(n=36)$, antibodies to all three PTM $(n=76)$ and antibody negative patients $(n=35)$. Overall there was low radiographic progression in this sample of the SERA cohort. EULAR non-responders had greater progression compared to good responders (Least square mean difference in SvH over $12 \mathrm{~m}$ of $1.6, \mathrm{p}=0.019$ ).

Baseline SvH erosion scores are 4.4 points higher in the CCP_Carb group compared to CCP alone $(p=0.009)$ (Table $2+$ Fig 1$)$.

Table 2

\begin{tabular}{lcc}
\hline Comparison & LS mean difference in baseline erosion score & P value \\
\hline CCP_Carb vs CCP & 4.4 & 0.009 \\
CCP_Carb vs CCP_Carb_Acet & 3.9 & 0.017 \\
CCP_Carb vs Negative & 4.3 & 0.026 \\
\hline Comparison & LS mean difference in SvH change over 12 months & P value \\
\hline CCP_Carb_Acet vs CCP & 1.3 & 0.016 \\
CCP_Carb_Acet vs Negative & 1.3 & 0.046 \\
\hline
\end{tabular}

Total $\mathrm{SvH} 12 \mathrm{~m}$ progression is 1.3 points higher in the triple positive group compared to the CCP group alone $(p=0.016)$ (Table $2+$ Fig 2$)$. Total SvH progression is also higher when comparing the triple positive to the negative group $(\mathrm{p}=0.046)$.

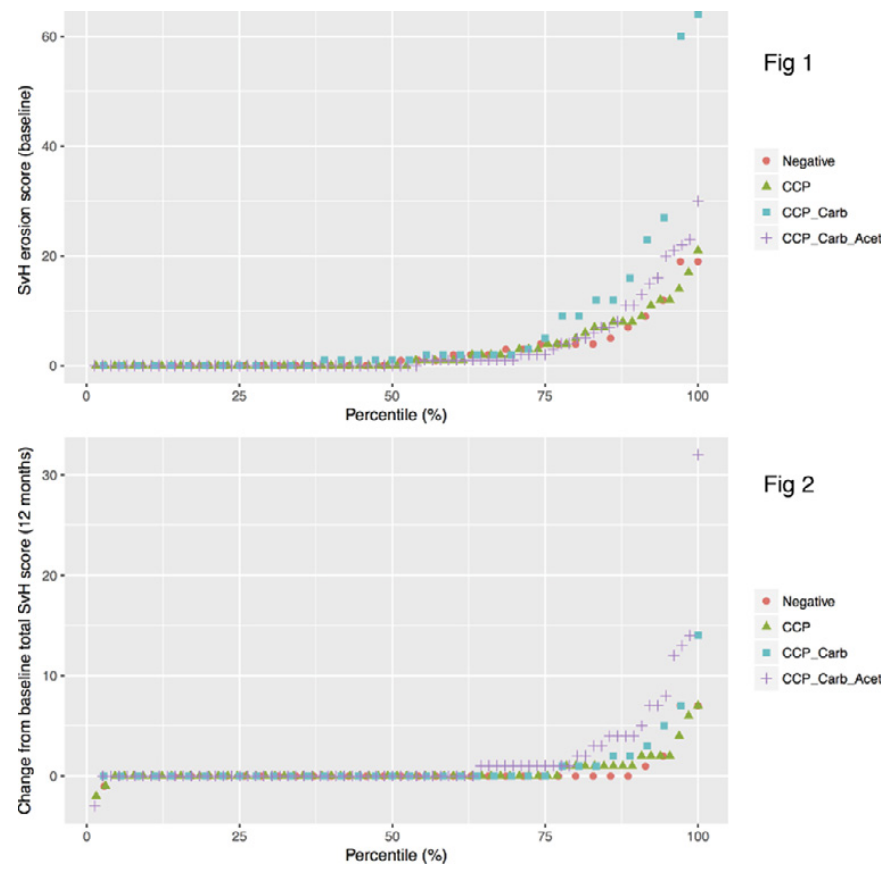

Conclusions: RA patients with antibodies to citrullinated peptides only have lower baseline erosions and less radiographic progression over $12 \mathrm{~m}$ compared to those with a wider autoantibody repertoire. Baseline differences in erosion suggest that these antibodies may be pathogenic during the pre-RA disease process. Radiographic progression increases with autoantibody repertoire suggesting ongoing immune activation.

Disclosure of Interest: J. Nijjar: None declared, F. Morton: None declared, A. Gilmour: None declared, C. Paterson: None declared, H. Bang Employee of: Orgentec Diagnostike $\mathrm{GmbH}$ and holds patent for mutated citrullinated vimentin as diagnostic tool, D. van der Heijde Employee of: Director of Imaging Rheumatology, K. Raza: None declared, C. Buckley: None declared, D. Porter Grant/research support from: Pfizer co-funded the SERA cohort, I. Mclnnes: None declared DOI: 10.1136/annrheumdis-2017-eular.2844

\section{THU0112 STRESS AND DEPRESSION IN PATIENTS WITH EARLY INFLAMMATORY POLYARTHRITIS: NATURAL HISTORY AND ASSOCIATIONS WITH DISEASE ACTIVITY, DISABILITY AND PAIN OVER FIVE YEARS}

J.M. Gwinnutt $^{1}$, D.P.M. Symmons ${ }^{1,2}$, A.J. MacGregor ${ }^{3,4}$, J.R. Chipping ${ }^{3,4}$, T. Marshall ${ }^{3,4}$, M. Lunt ${ }^{1}$, S.M.M. Verstappen ${ }^{1} .{ }^{1}$ Arthritis Research UK Centre for Epidemiology, University of Manchester; ${ }^{2}$ NIHR Manchester Musculoskeletal Biomedical Research Unit, Central Manchester University Hospitals NHS Foundation Trust, Manchester; ${ }^{3}$ Norwich Medical School, University of East Anglia; ${ }^{4}$ Rheumatology Department, Norfolk and Norwich University Hospitals NHS Trust, Norwich, United Kingdom

Background: Stress and depression are common in patients with inflammatory polyarthritis (IP). There is little research on long term patterns of depression and stress or how these variables relate to disease activity, disability and pain.

Objectives: To describe the natural history of stress and depression over five years and to assess the association of baseline, one year prior and current disease activity, disability and pain with longitudinal stress and depression.

Methods: Patients recruited to the Norfolk Arthritis Register (NOAR) (inclusion criteria: $\geq 2$ swollen joints for $\geq 4$ weeks) from 2005-2008 were included in this analysis. Demographics, medication use, 51 swollen/tender joint counts (SJC51/TJC51), pain visual analogue scale, HAQ, comorbidities and the Arthritis Impact Measurement Scales 2 (AIMS2) depression and stress subscales (range 0-10; high score $=$ worse health status) were collected at baseline and years 1, 2, 3 and 5. Rheumatoid factor (RF), anti-cyclic citrullinated peptide antibodies (anti-CCP2) and C-reactive protein (CRP) were measured in baseline blood samples. ACR/EULAR 2010 RA criteria were applied to baseline characteristics. Depression and stress over five years were described using descriptive statistics. Multivariate random effects models were applied to assess the association of baseline disease activity (SJC51/TJC51), pain and disability with depression and stress over time adjusting for baseline age, gender, RF, anti-CCP2, CRP, sDMARD use, comorbidities, depression and stress. Similar methods were used to assess one year prior and current disease activity, pain and disability's association with stress and depression. Missing data were imputed using multiple imputation.

Results: 509 patients were included (median (IQR) age: $57(45,68)$ years; $321(63.1 \%)$ female; 305 (59.9\%) ACR/EULAR RA). Baseline median (IQR) depression and stress were $2.5(1.5,4.5)$ and $4.0(2.5,5.5)$ respectively and remained constant over five years. Baseline SJC51, TJC51, pain and HAQ were not independently associated with depression or stress over five years. Current HAQ and pain, but not SJC51/TJC51, were independently associated with depression and stress (per unit increase in $\mathrm{HAQ}$ : depression $\beta 0.83,95 \% \mathrm{Cl}$ $0.69,0.97$; stress $\beta 0.76,95 \% \mathrm{Cl} 0.61,0.90$; per $1 \mathrm{~cm}$ increase in pain: depression $\beta 0.09,95 \% \mathrm{Cl} 0.06,0.12$; stress $\beta 0.09,95 \% \mathrm{Cl} 0.05,0.12)$. Higher HAQ was independently associated with increased depression and stress one assessment later (per unit increase in $\mathrm{HAQ}$ : depression $\beta 0.21,95 \% \mathrm{Cl} 0.09,0.32$; stress $\beta$ $0.21,95 \% \mathrm{Cl} 0.10,0.33$ ) but not pain, SJC51 or TJC51.

Conclusions: There were no associations between measures of disease activity and depression or stress. Prospectively higher HAQ scores were associated with worse psychological health a year later. This may have implications for holistic management of IP.

Disclosure of Interest: None declared

DOI: 10.1136/annrheumdis-2017-eular.3432

\section{THU0113 SERUM CALPROTECTIN MAY REFLECT INFLAMMATORY ACTIVITY IN PATIENTS WITH ACTIVE RHEUMATOID ARTHRITIS DESPITE NORMAL C-REACTIVE PROTEIN}

J. Hurnakova ${ }^{1}$, H. Hulejova ${ }^{1}$, J. Zavada ${ }^{1}$, M. Komarc ${ }^{2}$, L. Andres Cerezo ${ }^{1}$, H. Mann ${ }^{1}$, J. Vencovsky ${ }^{1}$, K. Pavelka ${ }^{1}$, L. Senolt ${ }^{1}$. ${ }^{1}$ Institute of Rheumatology, First Faculty of Medicine, Charles University, Prague, Czech Republic;

${ }^{2}$ Department of Methodology, Faculty of Physical Education and Sport, Charles University, Prague, Czech Republic

Background: About a half of patients with rheumatoid arthritis (RA) have normal or low C-reactive protein (CRP) levels ${ }^{1-3}$. Calprotectin is a promising and probably more specific biomarker of disease activity than conventionally used acute phase reactants.

Objectives: The aim of this study was to analyse levels of serum calprotectin in RA patients with clinically active disease and with low CRP $(<10 \mathrm{mg} / \mathrm{L})$.

Methods: A total of 160 RA patients and 32 healthy subjects were enrolled in this study. All patients underwent clinical examination (DAS28). The levels of calprotectin were analyzed in patients with moderate to high disease activity with low CRP levels and in healthy subjects. The discriminatory capacity of calprotectin to identify clinically active patients in spite of normal CRP was assessed using ROC curves.

Results: Out of all RA patients, 74/160 (46.3\%) had low CRP and were in remission or had low activity at the same time. However, 51/160 (32\%) had low CRP levels despite moderate to high disease activity according to DAS28. In these patients, calprotectin levels were significantly higher than in patients with low CRP in remission or with low disease activity at the same time (mean $2.7 \pm 1.5$ vs. $2.1 \pm 1.2 \mu \mathrm{g} / \mathrm{mL}, \mathrm{p}=0.043$ ) and differed from that in healthy subjects (mean $2.7 \pm 1.5$ vs. $\pm 1.9 \pm 1.2 \mu \mathrm{g} / \mathrm{mL}, \mathrm{p}=0.011$ ) (Figure 1 ). The discriminatory capacity for calprotectin to distinguish clinically active vs. inactive patients in spite of low CRP 